\title{
Botulinum A Toxin Treatment of Hemifacial Spasm and Blepharospasm
}

\author{
Young Choon Park, M.D., Jeong Keun Lim, M.D., \\ Dong Kuck Lee, M.D., Sang Doe Yi, M.D. \\ Department of Neurology, Keimyung University School of Medicine, \\ Taegu, Korea
}

\begin{abstract}
We studied the effects of botulinum $A$ toxin in 101 patients with hemifacial spasm and 11 patients with blepharospasm in an open trial and double blind manner. All patients in the open trial and 6 patients in the double blind trial improved after the first injection of botulinum toxin. There was no improvement with placebo.

The peak effect ranged from one to 6 days after injection and mean peak. effect was 3.6 days in blepharospasm, and 4 days in hemifacial spasm. Of 144 treatments, $98.6 \%$ had excellent results, (below grade I). The duration of beneficial effect ranged 11 to 40 weeks (mean 16.5 weeks) in hemifacial spasm and 9 to 30 weeks (mean 14.2 weeks) in blepharospasm.

Complications were encountered in $63.4 \%$ in hemifacial spasm and $72.7 \%$ in blepharospasm. The common side effects were dry eyes, mouth droop, $p$ tosis and lid edema in order of frequency. These side effects were mild and resolved spontaneously in 1 to 3 weeks. Botulinum A toxin therapy is effective and convenient, and the treatment of choice for patients with hemifacial spasm and blepharospasm.
\end{abstract}

Key Words: Botulinum A Toxin, Hemifacial Spasm, Blepharospasm, Complications.

\section{INTRODUCTION}

Since botulinum toxin type A was first used for the treatment of strabismus (Scott, 1973, 1980, 1981), a number of publications have reported that botulinum toxin was useful in the treatment of hemifacial spasm (HFS), blepharospasm (BS) and some other dystonic disorders (Report of the therapeutics and technology assessment subcommittee of the American academy of neurology, 1990; Jankovic and Brin, 1991; NIH consensus statement, 1991).

Address for correspondence: Young Choon Park, Department of Neurology, Keimyung University School of Medicine. 194 Dongsan Dong, Taegu, 700-310, Korea Tel: 053-250-7831

Presented at the 8th Asian and Oceanian congress of Neurology Tokyo, Sept, 2, 1991. Supported by Special Research Grant from Dongsan Medical Center (1991)
Hemifacial spasm is a chronic distressing movement disorder of the face characterized by unilateral twitching, tonic spasm and synkinesis of the muscles innervated by the facial nerve (Digre and Corbette, 1988). A vascular compression at the facial nerve root can be observed in $98 \%$ of patients with HFS at the time of surgery (Jannetta, 1982; Auger et al, 1986). A combination of facial nucleus hyperexcitability and a peripheral facial nerve involvement has been demonstrated by electrophysiologic studies in the majority of patients with HFS (Estaban and Molina-Negro, 1986). Blepharospasm is characterized by intermittent spasmodic involuntary contraction of the orbicularis oculi muscles due to unknown etiology (Jankovic and Orman, 1987).

Although some proposed medications have been helpful (Alexander and Moses 1982; Herzberg, 1985), most drugs (including herb medicine) and acupuncture are generally not effective in HFS and BS. Microsurgical decompression of the facial $n$ erve can be offered to patients with HFS and has 
Table 1. Age and Sex distribution of hemifacial spasm and blepharospasm

\begin{tabular}{|c|c|c|c|c|c|c|}
\hline \multirow[b]{2}{*}{$A g e^{\text {Sex }}$} & \multicolumn{3}{|c|}{ Hemifacial Spasm } & \multicolumn{3}{|c|}{ Blepharospasm } \\
\hline & Men & Women & Total & Men & Women & Total \\
\hline $20-29$ & & 1 & 1 & & & \\
\hline $30-39$ & 3 & 6 & 9 & & 2 & 2 \\
\hline $40-49$ & 11 & 14 & 25 & & 1 & 1 \\
\hline $50-59$ & 15 & 22 & 37 & 1 & 2 & 3 \\
\hline $60-69$ & 4 & 21 & 25 & 1 & 4 & 5 \\
\hline $70-79$ & 2 & 2 & 4 & & & \\
\hline Total & $\begin{array}{c}35 \\
(34.7)\end{array}$ & $\begin{array}{c}66 \\
(65.3)\end{array}$ & $\begin{array}{c}101 \\
(100 \%)\end{array}$ & $\begin{array}{c}2 \\
(18.2)\end{array}$ & $\begin{array}{c}9 \\
(81.8)\end{array}$ & $\begin{array}{c}11 \\
(100 \%)\end{array}$ \\
\hline \multicolumn{4}{|c|}{ Age range : $27-73$ years; } & \multicolumn{3}{|c|}{$38-66$ years } \\
\hline \multicolumn{2}{|c|}{ Mean age } & e: 53.3 & years; & \multicolumn{3}{|c|}{53.7 years } \\
\hline & & & years & \multicolumn{3}{|c|}{ Women : 52.6 years } \\
\hline
\end{tabular}

Table 2. Rating scale of intensity of facial and orbicularis muscle spasm

$\mathrm{o}=$ No spasm

I = mild, barely noticeable

II = mild, noticeable fluttering, no functional impairment

III = moderate spasm, moderate functional impairment

IV = severe incapacitating spasm

an $81-87.5 \%$ success rate, however serious complications occurred in 19\%-35\% (Loeser and Chen, 1983; Piatt and Wilkins, 1984; Auger et al, 1986).

We report the results and complications of botulinum A toxin treatment in 101 patients with HFS and 11 patents with $B S$.

\section{PATIENTS AND METHODS}

A total of 112 patients were treated with botulinum A toxin. Of these, 101 (90.2\%) had hemifacial spasm, and 11 (9.8\%) had essential blepharospasm. The age range of the patients was 27 to 73 years (mean, 53.5 years), prevalent age range was 40 to 69 years (81\%). The sex distribution included 75 (67.0\%) women and 37 (33.0\%) men (Table 1).

Before the treatment with botulinum toxin, an informed consent was obtained after explanation of the experimental nature of the study. A complete medical history and physical examination were recorded and an eye examination was done to
Table 3. Correlate grades of symptom with durations of symptom in hemifacial spasm and blepharospasm

\begin{tabular}{|c|c|c|c|c|c|c|c|c|}
\hline \multirow[b]{2}{*}{$\begin{array}{c}\text { Grades } \\
\text { Duration(yrs) }\end{array}$} & \multicolumn{5}{|c|}{ Hemifacial Spasm } & \multicolumn{3}{|c|}{ Blepharospasm } \\
\hline & 1 & II & III & IV & & III & IV & \\
\hline$<1$ & 1 & 4 & 3 & 3 & 11 & 2 & 3 & 5 \\
\hline $2-3$ & 1 & 4 & 6 & 10 & 21 & 1 & 4 & 5 \\
\hline $4-5$ & & 2 & 3 & 6 & 11 & & 1 & 1 \\
\hline $6-7$ & & 1 & 2 & 4 & 7 & & & \\
\hline $8-9$ & & 1 & 5 & 8 & 14 & & & \\
\hline $10-11$ & & & 5 & 12 & 17 & & & \\
\hline $12-13$ & & & 1 & 3 & 4 & & & \\
\hline $14-15$ & & & 2 & 3 & 5 & & & \\
\hline$>16$ & & & 1 & 10 & 11 & & & \\
\hline & 2 & 12 & 28 & 59 & & 3 & 8 & \\
\hline Total & & & & & 101 & & & 11 \\
\hline
\end{tabular}

rule out causes of secondary blepharospasm. Spontaneous facial or orbicularis spasm intensity was rated on a subjective scale of 0 to 4 (Table 2).

The duration of symptoms before botulinum $A$ toxin treatment ranged from 4 months to 35 years (mean 5.1 years). Symptom duration is longer in HFS (6 months to 35 years) than in BS (4 months to 4 years). Of our 101 patients with HFS, $86.1 \%$ belong to grade III or IV and all of the patients with BS had grade III or IV at the time of treatment. There was statistically significant positive correlation between grades of symptom and symptom durations in HFS $(P<0.005)$ (Table 3$)$.

Botulinum toxin type A (Oculinum Inc. lot number 79-11) was stored frozen at $-10^{\circ} \mathrm{C}$ until use. It was diluted in normal saline $4 \mathrm{ml}$ (2.5 units per 0.1 $\mathrm{ml}$ ) and used on the same day.

At first 8 patients with HFS and 4 patients with BS were randomized to receive, in a double blind trial, either the toxin or saline as a placebo. Later most of the patients (93 HFS, 7 BS) were included in an open trial.

The initial injection consisted of small doses (2.5 units-0.5 units) titrating them to the needs of the patients, to determine the range of effective dose. Botulinum A toxin was injected subcutaneously or intramusculary, into multiple sites of the face, the medial and lateral portions of the upper eyelid and the lateral and central portions of the lower eyelid, where greater spasm occured. Our patients were asked to call 3 to 6 days after injection and were examined. Videotapes were recorded before and 
Table 4. Doses of botulinum toxin for each treatment

\begin{tabular}{|c|c|c|c|c|c|c|c|c|c|}
\hline \multirow{3}{*}{$\begin{array}{l}\text { Botulinum } \\
\text { Toxin } \\
\text { (Units) }\end{array}$} & & \multicolumn{4}{|c|}{ Hemifacial Spasm } & \multicolumn{4}{|c|}{ Blepharospasm } \\
\hline & \multirow[b]{2}{*}{$1 s t$} & \multicolumn{3}{|c|}{$\begin{array}{l}\text { Additional } \\
\text { Injection }\end{array}$} & \multicolumn{5}{|c|}{$\begin{array}{l}\text { Injection for Injection for } \\
\text { Recurrence Recurrence }\end{array}$} \\
\hline & & 2nd & $3 r d$ & 4 th & 2nd & $3 r d$ & 1st & 2nd & 3rd \\
\hline $2.5-5.0$ & 5 & 18 & 11 & 2 & & & & & \\
\hline $7.5-10.0$ & 24 & 19 & 7 & 1 & 4 & 1 & & & \\
\hline $12.5-15.0$ & 48 & 7 & 2 & & 7 & 2 & 1 & & \\
\hline $17.5-20.0$ & 20 & 1 & & & 6 & 3 & 2 & & \\
\hline $22.5-25.0$ & 4 & & & & & & 6 & & \\
\hline $27.5-30.0$ & & & & & & & 2 & 2 & \\
\hline $32.5-35.0$ & & & & & & & & 3 & 1 \\
\hline $37.5-40.0$ & & & & & & & & 2 & 1 \\
\hline Total & 101 & 45 & 20 & 3 & 17 & 6 & 11 & 7 & 2 \\
\hline
\end{tabular}

* Mean dose of botulinum injection in each patient; Hemifacial Spasm:13.5 units, Blepharospasm:22 units

Table 5. Peak effect of therapy

\begin{tabular}{ccc}
\hline Days & HFS & BS \\
\hline 1 & 2 & \\
2 & 7 & 2 \\
3 & 21 & 3 \\
4 & 37 & 4 \\
5 & 30 & 1 \\
6 & 4 & 1 \\
\hline Total & 101 & 11 \\
\hline & Mean : 4.0days; & 3.6 days
\end{tabular}

at the first and second visits after injection.

A higher dose and multiple additional doses were needed according to the severity of muscle spasm or the degree of involved muscle. Seventyone percent of patients with HFS received $7.5 \mathrm{u}$ to $20 \mathrm{u}$ and $91 \%$ of patients with BS received $17.5 \mathrm{u}$ to $30 \mathrm{u}$ initially. The total dose of injections varied from 2.5 to $40 \mathrm{u}$ in each set of treatment. Mean doses of the toxin injection in each patient were $13.5 \mathrm{u}$ in HFS and $22 \mathrm{u}$ in BS. Patients with severe facial spasm were given multiple additional injections with intervals of one week. Our 112 patients underwent a total of 212 treatments between Feb. 1990 and March 1992. Of these, 68 patients (60. $7 \%$ ) had 2 to 4 additional injections for maximal benefit, and 24 ptients (24.4\%) had two sets of treatments and 8 patients (7.1\%) had three sets of treatments for recurrence. Recurrence was de- fined as reappearance of objective and subjective facial and/or orbicular spasm at least 8 weeks after maximal benefit from initial tretment (Table 4). Follow-up duration was 7 to 20 months.

\section{RESULTS}

One hundred and twelve patients (men 37 and women 75) were enrolled in this study.

All patients in the open trial and 6 patients in the double blind trial improved with the first injection of botulinum toxin. Six Patients with placebo injection did not improve.

Forty-five patients (44.6\%) with HFS had no maximal effect to inital doses of injection, and required 2 nd, 3rd (19.8\%) and 4th (3\%) additional smaller doses of injections (Table 4). Each additional dose of injection was given 7 to 10 days after previous injection.

Peak effect ranged from one to 6 days after injection, and mean peak effect was 4.0 days in HFS and 3.6 days in BS (Table 5).

Results of botulinum A toxin therapy are shown in Table 6. Of 144 treatments, 66 had grade 0 (45. $8 \%), 76$ had grade I (52.8\%), and only 2 had grade II (1.4\%). $98.6 \%$ of total treated patients had excellent result. Two patients belonging to grade II refused further injections.

The duration of beneficial effect ranged from 11 to 40 weeks (mean 16.5 weeks) in HFS and 9-30 weeks (mean 14.2 weeks) in BS.

We found that the duration of effect of botulinum therapy was longer in patients with less severe dyskinesia, enough therapeutic dose and suitable site of injections, and the duration of effect remained the same through subsequent treatments in the same patient.

Complications were encountered in $63.4 \%$ in HFS and $72.7 \%$ in BS. The most common side effect was dry eyes which was noted in 20 cases (19.8\%) in HFS and 3 cases (27.3\%) in BS, and mouth droop (facial weakness) was noted in 20 cases (19.8\%) in HFS. The second most frequent side effect was ptosis noted in $11(10.9 \%)$ in HFS and $3(27.3 \%)$ in BS (Table 7). Ptosis was mild, although complete ptosis was noted in 2 cases of HFS. In all cases, ptosis was temporary with a mean duration of 2 weeks (range, 1 week to 4 weeks). Ptosis was related to technical failure (injection near center of upper eyelid) or old aged patients who had loose connective tissue of the upper eyelid, so that injected toxin spread to the 
Table 6. Results of botulinum A toxin therapy

\begin{tabular}{|c|c|c|c|c|c|c|c|}
\hline \multirow{3}{*}{$\begin{array}{c}\text { Results } \\
0\end{array}$} & \multicolumn{6}{|c|}{ Hemifacial Spasm Blepharospasm } & \multirow[b]{2}{*}{ Total } \\
\hline & \multicolumn{3}{|c|}{ Men Women (\%) } & \multicolumn{3}{|c|}{ Men Women (\%) } & \\
\hline & 20 & 37 & $(46.0)$ & 2 & 7 & $(45.0)$ & $66(45.8)$ \\
\hline I & 23 & 42 & $(52.4)$ & 2 & 9 & $(55.0)$ & $76(52.8)$ \\
\hline$\|$ & 1 & 1 & $(1.6)$ & & & & $2(1.4)$ \\
\hline \multicolumn{8}{|l|}{ III } \\
\hline \multicolumn{8}{|l|}{ IV } \\
\hline \multirow[t]{2}{*}{ Total } & 44 & 80 & & 4 & 16 & & \\
\hline & \multicolumn{3}{|c|}{124} & \multicolumn{3}{|c|}{20} & $44(100.0)$ \\
\hline
\end{tabular}

Table 7. Complications of botulinum toxin therapy

\begin{tabular}{|c|c|c|c|c|}
\hline \multirow[b]{2}{*}{ Symptoms } & \multicolumn{2}{|c|}{ Hemifacial Spasm } & \multicolumn{2}{|c|}{ Blepharospasm } \\
\hline & 101 cases & $\%$ & 11 cases & $\%$ \\
\hline Dry eyes & 20 & 19.8 & 3 & 27.3 \\
\hline Mouth droop & 20 & 19.8 & & \\
\hline Ptosis & 11 & 10.9 & 3 & 27.3 \\
\hline Lid edema & 5 & 5.0 & 1 & 0.9 \\
\hline Fatigue & 4 & 4.0 & & \\
\hline Diplopia & 2 & 2.0 & 1 & 0.9 \\
\hline Ecchymosis & 2 & 2.0 & & \\
\hline Total & 64 & 63.4 & 8 & 72.7 \\
\hline
\end{tabular}

central part of the upper eyelid. Diplopia was noted in 3 cases $(2.7 \%)$. In one case from weakness of the lateral rectus muscle, in another from weakness of the inferior oblique muscle and in a third the cause the diplopia was unidentified. In all cases the diplopia subsided in 1 to 3 weeks. Other complications included lid edema in 6 cases, fatigability in 4 cases and ecchymosis at the injection site in 2 cases. These side effects resolved spontaneously in 1 to 3 weeks.

\section{DISCUSSION}

Botulinum A toxin treatment is currently recognized as an effective and safe therapy for hemifacial spasm, blepharospasm, spasmodic torticollis, oromandibular and laryngeal dystonia (NIH consensus statement, 1991).

Botulinum toxin is a complex protein produced by a gram gositive anaerobic bacterium Clostridium botulinum. Botulism is known as a cause of a serious and often fatal paralysis acquired through ingestion of contaminated food. The toxin causes muscle paralysis by blocking the presynaptic re- lease of acetylcholine at the neuromuscular junction (Kao et al, 1976).

Although botulinum toxin instructions from the Allegan $\mathrm{Co}$. indicated that the toxin dissolves in Sterile saline before use and that the toxin should be administered within 4 hours after reconstitution. We experienced almost the same effect up to 3 months after reconstitution if stored in a refrigerator $\left(-4 \sim-8^{\circ} \mathrm{C}\right)$.

The age range was $27-73$ years with a mean of 53 years in HFS, and 38-66 years with a mean of 53.7 years in BS in our study, which were not significantly different compared with the report of Dutton and Buckley (1988).

The mean peak effect after botulinum toxin injection was reported as 3-4 days (Elston, 1984), ranged from 12 hours to 2 days (Savino, 1985) in patients with HFS, which is comparable with our results, 4 days (ranged from 1-6 dyas)in HFS and 3.6 days (ranged from 2-6 days) in BS.

The mean duration of effect of botulinum toxin ranged from 11-15.3 weeks in HFS and 9.9-13.3 weeks in BS in the literature (Mauriello, 1985; Savino et al., 1985; Scott et al., 1985; Shorr et al., 1985; Tsoy et al., 1985; Dutton and Buckley, 1986, 1988; Elston, 1986; Frueh et al., 1986; Jankovic and Orman, 1987; Mauriello et al., 1987). In our data, the duration of beneficial effect of botulinum therapy ranged from 11-40 weeks with a mean duration of 16.5 weeks in patients with HFS, and ranged from 9-30 weeks, with a mean of 14.2 weeks in patients with BS. The duration of beneficial effect in patients with HFS was longer (2.3 weeks) than that of BS, as reported by Shorr et al. (1985) and Mauriello et al. (1987). Dutton and Buckley's data (1988) confirmed this impression with patients with HFS who had an average of 2.3 weeks longer effect than those with essential BS.

Although Scott et al. (1985) and Dutton et al. (1988) found no tendency toward an increased duration of effect in accordance with increasing toxin dose, we were impressed that a longer duraton of effect of botulinum toxin therapy was shown in milder degrees of dyskinesia as noted by Engstrom (1987), in enough dose of toxin, and in adequate site of injections. Frueh and Musch (1986) suggested that both the duration of spasm relief and the incidence of ptosis and diplopia are directly related to the botulinum toxin dose.

Although several studies have reported increasing duration of effect for the first two or three injections (Lingua, 1985; Frueh and Musch, 1986; Engstrom et al., 1987), Shorr et al.(1985) noted rather 
a decrease in duration of effect of the second injection compared with the first one. We observed no consistent tendency toward increasing or decreasing duration of effect for the first 3 toxin therapies, as noted by Scott et al. (1985), Gonnering, (1986) and Dutton and Buckley (1988). It has been reported that progressive decreasing effectiveness was due to formation of botulinum toxin antibody (Jankovic and Schwartz, 1991) or progressive muscular atrophy (Dutton and Buckley, 1988). However, Bigian et al. (1986) and Gonnering (1988) found no detectable antibodies in patients reciving up to five toxin treatments, and no significant atrophic changes have been detected in orbicularis muscles after 1 year of towin therapy by Wojno et al. (1986). Our study suggested that there was no significant loss of benefit even after repeated injections for 2 years.

The results revealed that the muscle spasms of HFS and BS are improved by multiple local injection of botulinum toxin. One hundred and twenty three $(98.4 \%)$ of 124 patients with HFS and all of 20 patients with BS improved below grade I. Only two patients with HFS remained grade II because they were reluctant to undergo additional injections after previous inadequate dose or unsuitable site of injection.

Frueh et al. (1986) has reported that duration of spasm relief and the incidence of ptosis and diplopia are directly related to the dose of botulinum toxin. When the dose was increased from 12.5 units to 25 units per eyelid, the duration of spasm relief increased only slightly but the incidence of ptosis and diplopia increased drastically. $\mathrm{He}$ concluded that a dose of 25 units per eyelid is too high and should not be used.

Side effects resulting from botulinum $A$ toxin have been reported in 20 to $65 \%$ of patients (Lingua, Scott et al., Shorr et al., 1985). In our study, side effects were found in $63.4 \%$ in HFS, and 72 . $7 \%$ in BS All local side effects were transient and mild, and disappeared without any sequelae within 1-3 weeks. No significant systemic side effects occurred in 212 sets of treatment. Four patients complained of general fatigue after the first injections, but the symptoms disappeared within a few days. Symtoms of dry eye and mouth droop on the side of injection were the most common side effect in our patients. Dry eye due to incomplete closure of the eye, lagophthalmos and poor blink was found in $19.8 \%$ of patients with HFS, and $27.3 \%$ in BS. Dry eye after toxin therapy has been reported in $4-65 \%$ of treatments by others (Mauriello, 1985;
Scott et al., 1985; Shorr et al., 1985; Frueh and Musch, 1986; Dutton and Buckley, 1988). Mouth droop which was attributed to transient weakness of the levator labii superioris, levator angli oris and zygomaticus major muscles after toxin injection was found in $19.8 \%$ of patients with HFS. Previous studies have reported facial weakness in 0 to $10 \%$ in BS and in 60 to $100 \%$ in those receiving mid and lower facial injections for Meige's syndrome or HFS (Lingua, Savino et al., 1985; Frueh and Musch, 1986; Dutton and Buckley, 1988). Ptosis was reported at an incidence of $0-53 \%$ (Savino et al., 1985; Shorr et al., 1985; Burns et al., 1986; Gonnering, 1986; Dutton and Buckley, 1988). In our study, ptosis presented for $2-3$ weeks in $10.9 \%$ in HFS and $27.3 \%$ in BS. Two of one hundred and one patients with HFS and 1 of 8 patients with BS developed unilateral complete ptosis due to overdose of toxin injection and spreading of toxin to the levator palpabrae muscle from the site of injection at the medial or lateral part of the upper eyelid as a result of structural loosening of the upper eyelid or rubbing of the injected upper eyelid by the patients themselves.

Eyelid edema and ecchymosis have been reported in 0.5\% (Jankovic and Orman, 1987) to $40 \%$ of toxin injections (Dutton and Buckley, 1988). We found transient lid edema in 5 cases $(5 \%)$ and local ecchymosis in 2 cases $(2 \%)$ at the site of injection. Diplopia was an uncommon side effect in $2.7 \%$ of our cases. The previous reported incidence was 0.5 to $7.1 \%$, but was much higher (20\%) when inexperienced doctors injected toxin too deeply into the eyelid (Frueh and Musch, 1985; Dutton and Buckley, 1988). Any external ocular muscle can be involved but the inferior oblique and lateral rectus muscles seem to be particularly vulnerable as in our cases because those are the most frequent sites of injection. Several systemic side effects after botulinum toxin injections have been reported, but their exact causes remain uncertain (Dutton and Buckley, 1988). Sanders et al. (1986) found abnormal neuromuscular transmission on muscles distant from eyelid injections with botulinum toxin within 24 hours of toxin injection. Dutton and Buckley (1988) reported that two of his patients experienced generalized weakness lasting 1-2 weeks, three patients had generalized pruritus lasting up to 2 weeks after toxin injection and another reported nausea of 3 weeks duration associated with botulinum $A$ toxin treatment. Although an overall complication rate was $63.4 \%$ in HFS and $72.2 \%$ in BS in our study, 
most side effects were mild, transient, local and subjectively preferable to chronic hemifacial or eyelid spasms. We concluded that local injections of botulinum $A$ toxin are effective, convenient and safe without serious side effect, and the treatment of choice for patients with HFS and BS.

\section{REFERENCES}

Alexander GE, Moses H: Carbamazepine for hemifacial spasm. Neurology 32:286-287, 1982.

Auger RG, Piepgras DG, Laws ER: Hemifacial spasm: Results of microvascular decompression of the facial nerve in 54 patients. Mayo Clin Proc 61:640-644, 1986.

Bigian Aw, Gonnering RS, Lockhart LB, Rabin B, Fuerste $\mathrm{FH}$ : Absence of antibody production in patients treated with botulinum A toxin. Am Ophthalmol 101:232235, 1986

Burns CL, Gammon JA, Gemmil MC: Ptosis associated with botulinum toxin treatment of strabismus and blepharospasm. Ophthalmology 93:1621-1627, 1986.

Digre K, Corbette JJ: Hemifacial spasm; differential diagnosis, mechanism, and treatment. Adv Neurol 49:151176, 1988.

Dutton JJ, Buckley EG: Botulinum toxin in the management of blempharospasm. Arch Neurol 43:380-382, 1986.

Dutton JJ, Buckley EG: Long-term results and complications of botulinum $A$ toxin in the treatment of blepharospasm. Ophthalmology 95:1529-1534, 1988.

Elston JS: Botulinum toxin treatment of hemifacial spasm. J Neurol Neurosurg Psychiatry 49:827-829, 1986.

Engstrom PF, Amoult JB, Mazow ML, Prager TC, Wilkins RB, Byrd WA, Hofmann RJ: Effectiveness of botulinum toxin therapy for essential blepharospasm. Ophthalmology 94:971-195, 1987.

Estaban A, Molina-Negro P: Primary hemifacial spasm: a neurophysiologic study, I Neurol Neurosurg Psychiatry 49:58-63, 1986.

Frueh BR, Musch DC: Treatment of facial spasm with botulinum toxin. Ophthalmol Plast Reconstr Surg 2:143146, 1986.

Gonnering RS: Negative antibody response to long term treatment of facial spasm with botulium toxin. Am J Ophthalmol 105:313-315, 1988.

Herzberg L: Management of hemifacial spasm with clonazepam. Neurology 35:1676-1677, 1985.

Jankovic j,: Brin M; Therapeutic uses of botulinum toxin. N Engl J Med. 324:1186-1194, 1991.

Jankovic J, Orman J: Botulinum A toxin for cranial-cervical dystonia: A double-blind, placebo-controlled study. Neurology 37:616-623, 1987.
Jankovic J, Schartz KS: Clinical correlates of response to botulinum toxin injections. Arch Neurol 48:1253-1256, 1991.

Jannetta PJ: Cranial rhizopathies in hemifacial spasm: In; Youmans JR, ed. Neurological Surgery; A Comprehensive reference guide to the diagnosis and management of neurological problems. 2nd ed. Vol. 6 , Philadelphia; WB Saunders Co, 3773-3775, 1982.

Kao I, Drachman DB, Price DL: Botulinum toxin: mechanism of presynaptic blockade. Science 193:12561258, 1976.

Lingua RW: Sequelae of botulinum toxin injection. Am J Ophthalmol 100:305-307, 1985.

Loeser JD. Chen J: Hemifacial spasm: treatment by microsurgical facial nerve decompression. Neurosurgery 13:141-146, 1983.

Mauriello Jr J A: Blepharospasm, Meige's syndrome, and hemifacial spasm: Treatment with botulinum toxin. Neurology 35:1499-1500, 1985.

Mauriello Jr J A, Coniaris $\mathrm{H}$, Haupt EJ: Use of botulinum toxin in the treatment of one hundred patients with facial dyskinesias. Ophthalmol 94:976-979, 1987.

National institutes of health consensus development conference statement, November 12-14, 1990; Clinical use of botulinum toxin. Arch Neurol 48: 1294-1298, 1991.

Piatt $\mathrm{JH}$, Wilkins $\mathrm{RH}$ : Treatment of tic douloureux and hemifacial spasm by posterior fossa exploration: therapeutic implications of various neurovasular relationship. Neurosurgery 14:462-471, 1984.

Report of the therapeutics and technology assessment subcommittee of the American Academy of Neurology: Assessment: The Clinical usefulness of botulinum toxin-A in treating neurological disorders. Neurology 40:9, 1990.

Sanders DB, Massey EW, Buckley EG: Botulinum toxin for blepharospasm: Single fiber EMG studies. Neurology 36:545-547, 1986.

Savino PJ, Sergott RC, Bosley TM, Schatz NT: Hemifacial spasm treated with botulinum $A$ toxin injection, Arch Ophthalmol 103:1305-1306, 1985.

Scott AB, Rosenbaum A, Collins C.C: Pharmacologic weakening of extraocular muscles. Invest Ophthalmol 12:924-927, 1973.

Scott AB: Botulinum toxin injection into extraocular muscles as an alternative to strabismus surgery, $J$ Pediatr Ophthalmol, Strabismus 17:21-25, 1980.

Scott AB: Botulinum toxin injection of eye muscles to correct strabismus. Trans Am Ophthalmol Soc 79:734770, 1981.

Scott AB, Kennedy RA, Stubbs HA: Botulinum A toxin injection as a treatment for blepharospasm. Arch Ophthalmol 103-347-350, 1985. 
Shorr N, Seiff SR, Kopelman J: The use of botulinum toxin in blepharospasm. Am J Ophthalmol 99:542-546, 1985.

Tsoy EA, Buckley EG, Dutton JJ: Treatment of blepharospasm with botulinum toxin. Am J Ophthalmol
99: 176-179, 1985.

Wojno T, Campbell P, Wright $\mathrm{J}$ : Orbicularis muscle pathology after botulinum toxin injection. Ophthalmol Plast Reconstr Surg 2:71-74, 1986. 